\title{
Gene expression of renal lactoferrin and glycemic homeostasis in diabetic rats with reference to the protective role of exogenous bovine lactoferrin
}

\author{
Sameer H. Qari ${ }^{1 *}$ and Kamal Attia ${ }^{1,2}$
}

\begin{abstract}
Background: This study is intended to clarify the influence of exogenous bovine lactoferrin (bLf) treatment on glycemic homeostasis, gene expression, and production of lactoferrin $(L f)$ in rats with experimentally induced diabetes.

Methodology: Fifty adult male rats were used; 15 rats were used as the normal control rats (group A) and were injected an intraperitoneal (I/P) with $1 \mathrm{ml}$ of isotonic saline daily for 3 months. Thirty-five rats were administered I/P injection of $60 \mathrm{mg}$ of streptozotocin per kilogram body weight to induce diabetes. Thirty streptozotocin-treated rats were selected and used as diabetic rats, and they were subdivided into 2 equal groups (15 rats each): the untreated diabetic group (group B) and treated diabetic group (group C). The rats in the diabetic group were administered an $\mathrm{I} / \mathrm{P}$ injection of $1 \mathrm{ml}$ of isotonic saline daily for 3 months, while rats in the diabetic treatment group were administered an I/P injection of $300 \mathrm{mg}$ of bLf/ $\mathrm{kg}$ body weight/day/3 months. At the end of the experiment, blood and renal tissue samples were collected from all rats. The levels of insulin, glucose, and lactoferrin in plasma were measured. Homeostatic model assessment for insulin resistance (HOMA-IR) was performed. The numbers of LfmRNA copies in renal tissue were assessed using quantitative RT-PCR. To measure Lf production in renal tissue, Western blot analysis was applied.
\end{abstract}

Results: The obtained data demonstrated that the treatment of diabetic rats with bLf maintained glycemic homeostasis at normal levels but increased the mRNA expression of renal Lf.

Conclusion: In diabetic rats, bovine lactoferrin treatment offers the potential for protection against incidences of insulin resistance (IR) by stimulating the suppressed expression and production of the LTF gene.

Keywords: Diabetes mellitus, Lactoferrin, Glycemic homeostasis, Gene expression, RT-PCR, Western blot analysis

\section{Background}

Lactoferrin (Lf) is a conjugated nonbinding protein in the transferrin family with pleiotropic biological and medical actions, including antineoplastic, immunomodulatory, and antimicrobial properties. A number of these properties do not seem to have connections with its

\footnotetext{
*Correspondence: shqari@uqu.edu.sa

'Biology Department, Aljumum University College, Umm Al-Qura University, Makkah, Saudi Arabia

Full list of author information is available at the end of the article
}

capability for iron binding (Eizirik, Colli, \& Ortis, 2009; Metz-Boutique et al., 1984). Lactoferrin includes two equal sections, the $\mathrm{N}$-lobe and $\mathrm{C}$-lobe, each comprising a single iron-active site.

While the N-lobe is believed to increase antimicrobial activities, the C-lobe undertakes many therapeutic activities that are still being investigated. It has previously been recognized that the C-lobe could potentially be used to treat diabetes, but the full elucidation of its exact function has not been undertaken (Sharma, Sinha,

\section{Springer Open}

(c) The Author(s). 2020 Open Access This article is licensed under a Creative Commons Attribution 4.0 International License, which permits use, sharing, adaptation, distribution and reproduction in any medium or format, as long as you give appropriate credit to the original author(s) and the source, provide a link to the Creative Commons licence, and indicate if changes were made. The images or other third party material in this article are included in the article's Creative Commons licence, unless indicated otherwise in a credit line to the material. If material is not included in the article's Creative Commons licence and your intended use is not permitted by statutory regulation or exceeds the permitted use, you will need to obtain permission directly from the copyright holder. To view a copy of this licence, visit http://creativecommons.org/licenses/by/4.0/. 
Kaushik, Kaur, \& Singh, 2013). The C-lobe modulates inflammatory and immune responses through the downregulation of numerous cytokines, interleukin 6, granulocyte-macrophage colony-stimulating factor (GMCSF), and tumor necrosis factor A (Machnicki, Zimecki, \& Zagulski, 1993; Pammi \& Abrams, 2019). On the basis of its expression pattern and thus its biological properties, lactoferrin is one of the components of the innate immune system and works in the first line of immune defense (Brock, 1995).

The role of Lf in combating diabetes has been demonstrated empirically through the clinical outcomes of improved glycolytic equilibrium and dyslipidemia profiles, and anti-inflammatory effects. A number of experimental and clinical studies have reported these results for Lf (Agrawal, Tantia, Jain, Agrawal, \& Agrawal, 2013). Hypolipidemic, hypoglycemic, and other anti-inflammatory outcomes undergo modulation through the TLR-4/NF$\kappa \mathrm{B} / \mathrm{SIRT}-1$ axis, a key signaling pathway that is well known to be an activator of inflammation transcription regulators (Fuentes-Antrás, Ioan, Tueen, Egido, \& Lorenzo, 2014).

Teng (2006) reported that when nuclear receptors and transcription factors regulate gene expression, the joint action of multiple proteins is involved. Transcriptional activation takes place due to coregulation recruitment, binding with the response element of the promoter through nuclear receptors or transcription elements, and modification of chromatin granules. Although additional data regarding the general role and molecular mechanisms of Lf in gene regulation have recently been reported, there is very little available information regarding lactoferrin gene regulation in this field.

Although therapies for type II diabetes mellitus (T2DM) are available, there are still challenges regarding fluctuations in glucose levels and insulin resistance (Golden \& Sapir, 2012). As the aims of new therapies are to improve insulin resistance and mitigate both the short- and long-term effects of T2DM, this research is intended to examine the influence of exogenous bovine lactoferrin administration to rats with experimentally induced diabetes in terms of renal LTF gene expression and glycemic homeostasis.

\section{Materials and methods \\ Chemicals}

Chemicals were purchased from Sigma-Aldrich. Immunoblotting antibodies (anti-rat Lf, anti- $\beta$-actin, and horseradish peroxidase-conjugated secondary antibodies) were purchased from Biotechnology, Sigma, and Jackson Laboratory (USA), respectively. Additionally, proteinase inhibitor cocktails were obtained from Sigma-Aldrich (USA), and nitrocellulose membrane pore size $0.2 \mu \mathrm{m}$
(PS $0.2 \mu \mathrm{m}$ ) were supplied by Thomas Scientific (USA). The Pierce BCA kit was purchased from Thermo Fisher Scientific, Inc. (Rockford, USA).

\section{Animals}

This study was undertaken at the Department of Biology, University College, Al-Jumum, Umm Al-Qura University, Makkah, Saudi Arabia, between June and August 2019, using 50 male Sprague-Dawley rats with an average weight of $200 \mathrm{~g}$. These animals were kept at regulated temperatures of $24 \pm 1{ }^{\circ} \mathrm{C}$ on a 12 -hour day/night cycle (light between 7 a.m. and 7 p.m.). They had unlimited water and standard food with a calorific value of $3.45 \mathrm{kcal} / \mathrm{g}$; the food comprised $51 \%$ nitrogen, $6.6 \%$ ash, $4.5 \%$ fiber, $4.6 \%$ fat, and $24.9 \%$ protein. Fifteen rats were used as controls. Diabetes mellitus (DM) was induced in the other 35 rats through intraperitoneal (IP) injections of streptozotocin at $60 \mathrm{mg} / \mathrm{kg}$ of body weight. Blood samples were tested for hyperglycemia ( $>300 \mathrm{mg} / \mathrm{dL}$ ) to verify the presence of diabetes $48 \mathrm{~h}$ after injection. Thirty rats with glucose levels higher than $300 \mathrm{mg} / \mathrm{dL}$ were regarded as diabetic. The analysis procedures employed by this research were approved by the ethical committee of the institution.

\section{Experimental groups}

The rats in this experiment were split into the following three groups: group A, controls $(n=15)$ orally administered $1 \mathrm{ml}$ of isotonic saline each day for 3 months; group $\mathrm{B}$, diabetic rats $(n=15)$ orally administered $1 \mathrm{ml}$ of isotonic saline each day for 3 months; and group C, diabetic rats $(n=15)$ orally administered $300 \mathrm{mg}$ of bovine lactoferrin per kilogram of body weight (Radiance Nutritional Company, New Zealand) daily for 3 months (Hegazy, Salama, Mansour, \& Hassan, 2016).

\section{Sampling and measurements Determination of plasma glucose, insulin, and lactoferrin levels}

At the end of the experimental period (3 months), morning fasting plasma samples were collected from each group of rats. Glucose analysis was undertaken using the glucose oxidase method (Trindler, 1969). Insulin levels were assessed using ultrasensitive insulin ELISA to quantify the concentration of insulin protein in plasma samples (ALPCO, USA). Insulin resistance (IR) was determined through the HOMA test by using the following equation: insulin (fasting level in $\mu \mathrm{U} / \mathrm{mL}$ ) $\times$ glucose (fasting level in $\mathrm{mmol} / \mathrm{L}$ ) $/ 22.5$ (Antuna-Puente et al., 2011). For each group, the plasma Lf concentration was assayed by employing an enzyme-linked immunosorbent serologic assay kit (Assaypro EL2011-1, St. Charles, USA). A monoclonal 
antibody specific for rat Lf was precoated on a microplate. The intra- and interassay coefficients of variation were $4.8 \%$ and $7.3 \%$, respectively. The crossreactivity was less than $1 \%$.

\section{Renal tissue homogenate}

Directly after blood sampling, the rats were anesthetized with ether and killed by cervical dislocation. The kidneys of all rats were immediately removed and washed with PBS to remove excess blood. Weighed samples were collected from all the kidneys and homogenized (Omni $(\mathrm{TH})$ homogenizer, MSC, Ireland) in PBS to provide $20 \%$ homogenate that was stored at $-70{ }^{\circ} \mathrm{C}$ until needed for the extraction of RNA.

\section{Quantitative reverse transcription-PCR (RT-qPCR) assay}

The numbers of messenger RNA (mRNA) copies of lactoferrin LTF gene (ACCE: KT006756) was derived through quantitative reverse transcription (RT-PCR) in RNA concentrates of renal tissue homogenates from each rat group. For RNA purification, we used the RNeasy Mini Kit (QIAGEN, Germany) in accordance with manufacturer protocols. A detection system (The StepOnePlus $^{\text {Tix }}$ Real-Time PCR, Thermo Fisher, USA) and a specific diagnostic kit (SNP, i-DNA Biotechnology Pte Ltd., Singapore) were employed to perform RT-PCR assays for the determination of the specific quantities of rat Lf, in accordance with manufacturer instructions. Real-time complementary DNA (cDNA) amplification was performed in duplicate using the fluorescent dye SYBR Green. Target LTF gene amplification was normalized with the expression levels of ATP synthase 5 subunit O (ATP5O), which has no associations with the test variables under consideration in this research. The sequences of the primers used in RT-qPCR were as follows: for rat Lf, forward primer 5'-GAACCGTACT TCAGCTACTCTG-3' and reverse primer $5^{\prime}$-CTCATA CTCGTCCCTTTCAGC-3'; for ATP5O, forward primer 5'-GCGATGCTTCAGTACCTCTG-3' and reverse primer 5' -TGGCATAGCGACCTTCAATA-3'.

\section{Western blot analysis}

Renal tissue samples were minced on ice with scissors and then homogenized using the pestle of a glass Teflon homogenizer in $20 \mathrm{~mL}$ of RIPA lysis buffer $(150 \mathrm{mM}$ $\mathrm{NaCl}, 25 \mathrm{mM}$ Tris- $\mathrm{HCl}$ [pH 7.4], 0.1\% SDS, 40\% Nonidet $\mathrm{P}$, and $1 \mathrm{mM}$ EDTA) that contained $1 \%(\mathrm{w} / \mathrm{v})$ proteinase inhibitor cocktail $(104 \mathrm{mM}$ aprotinin, $80 \mathrm{mM}$ AEBSF, $3.6 \mathrm{mM}$ betatin, $2.1 \mathrm{mM}$ leupeptin, $1.4 \mathrm{mM}$ E64 , and $1.5 \mathrm{mM}$ pepstatin A). The tissue homogenates were then sonicated using a Sonic Dismembrator FB505 (Fisher, New Boston, USA) set at 15 for a minimum of three 5-s bursts prior to centrifugation for $40 \mathrm{~min}$ at 14, $000 \mathrm{rpm}$ and $48^{\circ}$ (Beckman Coulter Microfuge R,
Schaumburg Il). The supernatants were removed and stored at $-70{ }^{\circ} \mathrm{C}$ until required. A Pierce BCA kit was used to assess the total protein.

Protein extracts $(55 \mu \mathrm{g})$ were separated by SDS-PAGE $(10 \%)$ and then electroblotted into a $100 \%$ Triton-free nitrocellulose membrane (PS $0.2 \mu \mathrm{m}$ ). Anti-rat Lf antibody (1:2000, $78 \mathrm{kDa}$ band), anti- $\beta$-actin antibody (1: $40000,42 \mathrm{kDa}$ band), and horseradish peroxidaseconjugated secondary antibodies $(1 / 10000)$ were employed for immunoblotting. To confirm equal loading, $\beta$-actin protein expression was quantified. Five micrograms of purified rat lactoferrin was used as a standard. Equal loading was confirmed through determination of $\beta$-actin protein expression.

\section{Statistical analysis}

For quantitative data, the data are represented as the mean \pm SE. One-way analysis of variance (ANOVA) was employed to assess variations between groups, with a $p$ value of 0.05 or lower being regarded as having statistical significance. The statistics were analyzed using SPSS version 14.0 for Windows.

\section{Results}

Plasma glucose, insulin, and lactoferrin levels and HOMAIR index

The mean values of lactoferrin, HOMA-IR index, insulin, and glucose in all three test groups of rats are shown in Table 1. The analysis of the data showed that there is a significant decrease in plasma glucose levels $(p \leq 0.05)$ in treated diabetic rats compared to untreated diabetic rats; however, the plasma glucose level of treated diabetic rats was significantly greater than that of the control rats. There was a demonstrable decrease in insulin levels in both treated and nontreated rats with diabetes compared to the control rats $(p \leq 0.05)$. The lactoferrin levels were significantly lowered in untreated diabetic rats and significantly increased in treated diabetic rats $(p \leq 0.05)$. HOMA-IR showed a significant increase in untreated

Table 1 Plasma levels of glucose, insulin, and lactoferrin and the HOMA-IR index in the renal tissue of control rats, untreated diabetic rats, and diabetic rats treated with $L f(300 \mathrm{mg} / \mathrm{kg}$ ) for 3 months

\begin{tabular}{llll}
\hline Parameters & Control & Diabetic & Diabetic + lactoferrin \\
\hline Glucose $(\mathrm{mmol} / \mathrm{L})$ & $5.22 \pm 0.80$ & $24.25 \pm 1.20^{\mathrm{a}}$ & $8.35 \pm 0.90^{\mathrm{a}}$ \\
Insulin $(\mu \mathrm{U} / \mathrm{mL})$ & $20.40 \pm 2.17$ & $7.75 \pm 0.15^{\mathrm{a}}$ & $15.50 \pm 1.60^{\mathrm{a}}$ \\
Lactoferrin $(\mathrm{ng} / \mathrm{mL})$ & $155.45 \pm 6.50$ & $38.23 \pm 2.40^{\mathrm{a}}$ & $195.15 \pm 11.20^{\mathrm{a}}$ \\
HOMA-IR index & $4.73 \pm 0.90$ & $8.35 \pm 0.12^{\mathrm{a}}$ & $5.75 \pm 0.85$ \\
\hline
\end{tabular}

Values are mean $\pm \mathrm{SE}$

${ }^{\text {a}}$ Significantly different than the corresponding control value $(p \leq 0.05)$ 
diabetic rats $(p \leq 0.05)$, with no significant difference between treated diabetic rats and the controls.

\section{RT-PCR quantification of lactoferrin mRNA and Western blot analysis}

Figures 1 and 2 present the outcomes of Western blot analysis and quantitative RT-qPCR analysis for the control, untreated diabetic, and treated diabetic rats. The data show the gene expression of Lf in the diabetic rats, and the results indicate that the mRNA and protein expression of Lf was significantly decreased in untreated diabetic rats compared to control rats $(p \leq 0.05)$. Compared with both untreated diabetic rats and control rats, the diabetic rats treated with Lf showed significant increases in the expression level of Lf protein and qPCR products $(p \leq 0.05)$.

\section{Discussion}

This research demonstrates counteractive increases in blood Lf alongside improvements in glycemic parameters in diabetic rats, as shown in Table 1. The researchers attempted to detail the association between exogenous lactoferrin administration and glucose homeostasis parameters, including insulin and fasting glucose levels, in diabetic rats. Additionally, the chances of insulin resistance were calculated via the HOMA-IR index.

Insulin levels were significantly increased, and blood glucose was decreased (but remained greater than the control levels) by lactoferrin administration; the fact that the HOMA-IR index remained normal excluded the influence of IR. It was demonstrated that lactoferrin causes hypoglycemic effects through both an insulin-like influence and insulin-sensitizing properties (Gupta, Kono, \& Evans-Molina, 2010). Compared to the control condition, exogenous Lf treatment significantly increased insulin levels in blood. Research has shown that diet is a significant factor that influences insulin signaling and similar functions, including decreased oxidative stress, increased glucose disappearance rates, and increased insulin receptor expression in mature adipocytes (MorenoNavarrete et al., 2013).

Furthermore, it has been demonstrated that Lf combats diabetes via anti-inflammatory actions, ameliorating dyslipidemia, and maintaining glucose homeostasis. Numerous experimental and clinical studies have found a similar antidiabetic influence (Agrawal et al., 2013), but the precise pathway has never been fully explained. The hypoglycemic and concomitant anti-inflammatory effects are modulated by the TLR-4/NF-kB/SIRT-1 axis, a key signaling pathway that activates the transcription of inflammatory regulators (Fuentes-Antrás et al., 2014; Mohamed \& Schaalan, 2018). Furthermore, cell-based research showed that Lf significantly decreases the levels of intracellular reactive oxygen species (ROS) in a dosedependent manner and protected against oxidative stress (El-Desouky, Osman, Shams Eldin, \& Emaraa, 2017).

\section{RT-PCR quantification of lactoferrin mRNA and Western blot analysis}

The findings demonstrated a significant increase in the protein and mRNA levels of Lf in the renal tissue of rats treated with bLf compared to that of untreated diabetic rats and control rats. Recent reports suggested that Lf can be transported through partial membranes into certain cell nuclei and that it can bind to specific sequences of DNA, causing transcriptional activation ( $\mathrm{He} \&$ Furmanski, 1995). It has been suggested that Lf is able to bind to DNA (Garre, Bianchi-Scarra, Sirito, \& Ravazzolo, 1992) and that it is capable of mitigating oxidative stress (El-Desouky et al., 2017).

Lf cloning has been accomplished with a number of types of livestock, and the Lf cDNA and genes in mice

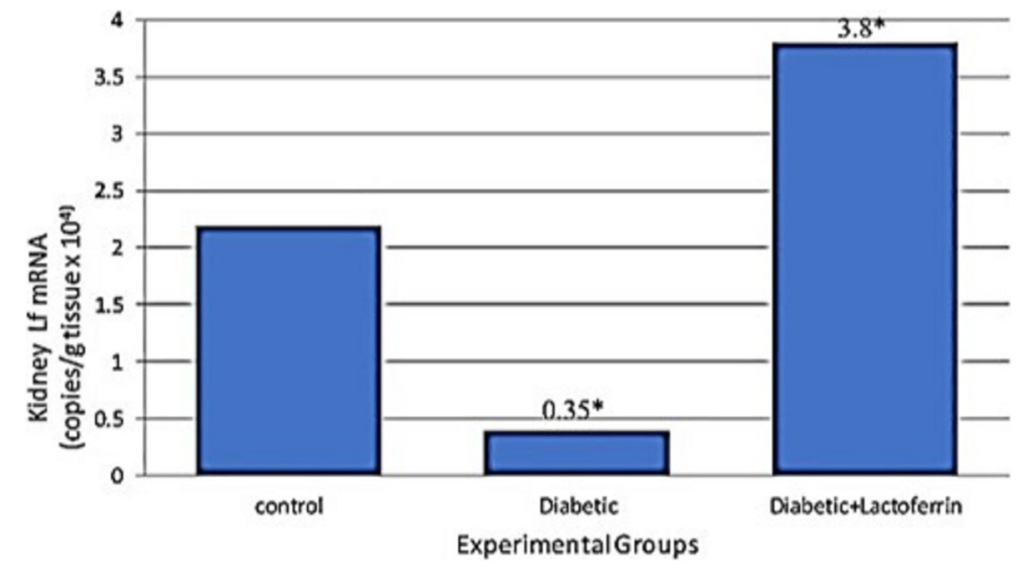

Fig. 1 Copies of Lf mRNA in the renal tissue of control rats, untreated diabetic rats, and diabetic rats treated with $\mathrm{Lf}(300 \mathrm{mg} / \mathrm{kg})$ for $3 \mathrm{months}$. Asterisk indicates the significant variation from the control group at $p<0.05$ 


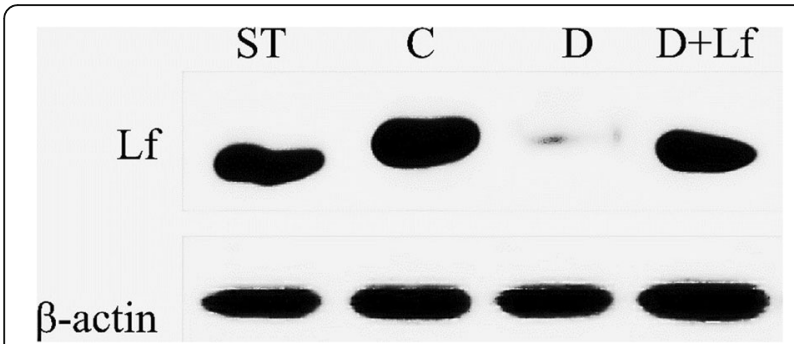

Fig. 2 Western blot detection of lactoferrin in the renal tissue of (C) control rats, (D) untreated diabetic rats, and (D+Lf) diabetic rats treated with $\mathrm{Lf}(300 \mathrm{mg} / \mathrm{kg})$ for 3 months. $\beta$-actin was used as a loading control

have been isolated and characterized in the laboratory (Cunningham, Headon, \& Conneely, 1992). Furthermore, reports have suggested a number of regions of the lactoferrin gene and protein products have high sequence homology among a variety of species (Teng, 2002); polyclonal rabbit antiserum developed to target mouse or human lactoferrin may undergo cross-reactions with lactoferrin if introduced to samples from other types of rodents.

Recent research has demonstrated that the administration of lactoferrin to mice causes autopotentiated increases in the expression of the LTF gene. Decreases in lactoferrin mRNA levels associated with diabetes were also found in the adipose tissues of mice (MorenoNavarrete et al., 2013); these results support the findings recorded in the current study.

It has been reported that Lf gene expression is inducible and constitutive and is specific to certain species, tissues, and cell types (Zheng, Ather, Sonstegard, \& Kerr, 2005). The regulation of LTF gene expression is complicated, and this regulatory process responds to diet, cell developmental stage, pathogen attack, and hormone levels (Li, Limmon, Imani, \& Teng, 2009). Notably, acute kidney injuries are linked to variations in the renal expression of the LTF gene (Famulski, Reeve, \& de Freitas, 2013).

In the current research, decreased lactoferrin gene expression found in diabetic rats may be attributable to the excess production of inflammatory cytokines associated with diabetic hyperglycemia, e.g., TNF- $\alpha$ and IL-6, which can induce the production of C-reactive protein (CRP), an inflammatory protein, that causes dysfunction in renal endothelial cells (Ramasamy, Yan, \& Schmidt, 2012). A significant amount of research has demonstrated that in diabetic rats, treatment with Lf significantly downregulated the increases in serum TNF- $\alpha$ and IL-6 cytokines (Zimecki, Dawiskiba, Zawirska, Krawczyk, \& Kruzel, 2003). If this is the case, this offers an explanation for the stimulating effect of exogenous bLf treatment on $L T F$ gene expression.

\section{Conclusion}

In diabetic rats, treatment with bLf allowed for the maintenance of normal glucose homeostasis, which reduced the incidence of IR. Increased Lf levels were shown to be associated with increases in renal Lf expression and protein production; this effect may have been caused by a decrease in the expression of inflammatory cytokines, although this requires further research. The outcomes demonstrated that Lf treatment has the potential to protect against the suppressed $L T F$ gene expression and increased IR in DM.

\section{Abbreviations}

bLf: Bovine lactoferrin; Lf: Lactoferrin; I/P: Intraperitoneal; STZ: Streptozotocin; HOMA-IR: Homeostatic model assessment of insulin resistance;

mRNA: Messenger ribonucleic acid; RT-PCR: Real-time polymerase chain reaction; IR: Insulin resistance; DM: Diabetes mellitus; RT-qPCR: Quantitative reverse transcription-polymerase chain reaction; ELISA: Enzyme-linked immunosorbent assay; T2DM: Type 2 diabetes mellitus; TLR-4: Toll-like receptor 4; NF-kB: Nuclear factor- kB; SIRT-1: Sirtuin-1; GM-CSF: Granulocytemacrophage colony-stimulating factor; cDNA: Cloned deoxyribonucleic acid

\section{Acknowledgements}

The authors wish to thank the Central Lab of Research and Graduate Studies in Aljumum University College - Umm Al-Qura University for its kind help.

\section{Authors' contributions}

Qari and Attia conceived the study, conducted the experiments, and wrote the manuscript. Attia analyzed the data. Both authors read and approved the final version.

\section{Funding}

Funding for this study was obtained through the budget of scientific research at Umm Al-Qura University in Saudi Arabia.

Availability of data and materials

Not applicable.

\section{Ethics approval}

Animals were treated according to the national and international ethics guidelines stated by the ethics committee of Umm Al-Qura University, and all procedures and experiments were performed according to the protocol approved by this ethics committee. The earliest scientifically justified endpoint was used in this study to prevent pain or distress in the experimental animals.

\section{Consent for publication}

Not applicable.

\section{Competing interests}

The authors declare that they have no competing interests.

\section{Author details}

${ }^{1}$ Biology Department, Aljumum University College, Umm Al-Qura University, Makkah, Saudi Arabia. ${ }^{2}$ Physiology Department, Faculty of Veterinary Medicine, Cairo University, Giza, Egypt.

Received: 11 October 2019 Accepted: 19 March 2020

Published online: 06 April 2020

\section{References}

Agrawal, R., Tantia, P., Jain, S., Agrawal, R., \& Agrawal, V. (2013). Camel milk: a possible boon for type 1 diabetic patients. Cellular and Molecular Biology, 59(1), 99-107.

Antuna-Puente, B., Disse, E., Rabasa-Lhoret, R., Laville, M., Capeau, J., \& Bastard, J. (2011). How can we measure insulin sensitivity/resistance. Diabetes \& Metabolism, 37(3), 179-188. 
Brock, J. (1995). Lactoferrin-a multifunctional immunoregulatory protein Immunology Today, 16, 417-419.

Cunningham, G., Headon, D., \& Conneely, O. (1992). Structural organization of the mouse lactoferrin gene. Biochemical and Biophysical Research Communications, 189, 1725-1731.

Eizirik, D., Colli, M., \& Ortis, F. (2009). The role of inflammation in insulitis and betacell loss in type 1 diabetes. National Review of Endocrinology, 5 , 219-226.

El-Desouky, M., Osman, S., Shams Eldin, N., \& Emaraa, I. (2017). Arginase enzyme activity and lactoferrin protein concentration in Egyptian diabetic patients. International Journal of Advanced Researches, 5(1), 1518-1523.

Famulski, K., Reeve, J., \& de Freitas, D. (2013). Kidney transplants with progressing chronic diseases express high levels of acute kidney injury transcripts: AKI signal in transplants with CKD. American Journal of Transplantation, 13, 634-644.

Fuentes-Antrás, J., loan, A., Tueen, J., Egido, J., \& Lorenzo, O. (2014). Activation of tollike receptors and inflammasome complexes in the diabetic cardiomyopathy- associated inflammation. International Journal of Endocrinology, 5, 827-847.

Garre, C., Bianchi-Scarra, M., Sirito, M., \& Ravazzolo, R. (1992). Lactoferrin binding sites and nuclear localization in K562(S) cells. Journal of Cellular Physiology, 153, 477-487

Golden, S., \& Sapir, T. (2012). Methods for insulin delivery and glucose monitoring in diabetes: summary of a comparative effectiveness review. Journal of Managed Care Pharmacy, 18, 1-17.

Gupta, D., Kono, T., \& Evans-Molina, C. (2010). The role of peroxisome proliferatoractivated receptor $\gamma$ in pancreatic $\beta$ cell function and survival: therapeutic implications for the treatment of type 2 diabetes mellitus. Diabetes Obesty and Metabolism, 12(12), 1036-1047.

He, J., \& Furmanski, P. (1995). Sequence specificity and transcriptional activation in the binding of lactoferrin to DNA. Nature, 373, 721-729.

Hegazy, R., Salama, A., Mansour, D., \& Hassan, A. (2016). Renoprotective effect of lactoferrin against chromium-induced acute kidney injury in rats: involvement of IL-18 and IGF-1 inhibition. PLoS One journal, 18, 302-309.

Li, Y., Limmon, F., Imani, F., \& Teng, C. (2009). Induction of lactoferrin gene expression by innate immune stimuli in mouse mammary epithelial $\mathrm{HC}-11$ cells. Biochimie, 91, 58-67.

Machnicki, M., Zimecki, M., \& Zagulski, T. (1993). Lactoferrin regulates the release of tumor necrosis factor a and interleukin 6 in vivo. International Journal of Experimental Pathology, 74, 433-439.

Metz-Boutique, M., Jolles, J., Mazurier, J., Schoentgen, F., Legrand, D., Spik, G., ... Jolles, P. (1984). Human lactotransferrin: amino acid sequence and structural comparisons with other transferrins. Eurobian Journal of Biochemistry, 145, 659-676.

Mohamed, W. A., \& Schaalan, M. F. (2018). Antidiabetic efficacy of lactoferrin in type 2 diabetic pediatrics; controlling impact on PPAR- $\gamma$, SIRT-1, and TLR4 downstream signaling pathway. Diabetes and Metabolic Syndroms, 10, 89 1-12.

Moreno-Navarrete, J., Serrano, M., Sabater, M., Ortega, F., Serino, M., \& Pueyo, N. (2013). Study of lactoferrin gene expression in human and mouse adipose tissue, human preadipocytes and mouse 3T3-L1 fibroblasts. Association with adipogenic and inflammatory markers. The Journal of Nutritional Biochemistry, 24(7), 1266-1275.

Pammi, M., \& Abrams, S. A. (2019). Enteral lactoferrin for the treatment of sepsis and necrotizing enterocolitis in neonates. Cochrane Database of Systematic Reviews, 11(5), 1-11.

Ramasamy, R., Yan, S. F., \& Schmidt, A. M. (2012). The diverse ligand repertoire of the receptor for advanced glycation end products and pathways to the complications of diabetes. Vascular Pharmacol, 57, 160-167.

Sharma, S., Sinha, M., Kaushik, S., Kaur, P., \& Singh, T. P. (2013). C-lobe of lactoferrin: the whole story of the half-molecule. Biochemistry Research International, 13, 271-284.

Teng, C. T. (2002). Lactoferrin gene expression and regulation: an overview. Biochemistry and Cell Biology, 80, 7-16.

Teng, C. T. (2006). Factors regulating lactoferrin gene expression. Biochemistry and Cell Biology, 84(3), 263-267.

Trindler, P. (1969). Determination of glucose in blood using glucose oxidase with an alternative oxygen.6. acceptor. Annals of Clinical Biochemistry, 6, 24-27.

Zheng, J., Ather, T., Sonstegard, T., \& Kerr, D. (2005). Characterization of the infection-responsive bovine lactoferrin promoter. Gene, 353, 107-117.
Zimecki, M., Dawiskiba, J., Zawirska, B., Krawczyk, Z., \& Kruzel, M. (2003). Bovine lactoferrin decreases istopathological changes in the liver and regulates cytokine production by splenocytes of obstructive jaundiced rats. Inflammation Research, 52, 305-310.

\section{Publisher's Note}

Springer Nature remains neutral with regard to jurisdictional claims in published maps and institutional affiliations.

\section{Submit your manuscript to a SpringerOpen ${ }^{\circ}$ journal and benefit from:}

- Convenient online submission

- Rigorous peer review

- Open access: articles freely available online

- High visibility within the field

- Retaining the copyright to your article

Submit your next manuscript at $\boldsymbol{\nabla}$ springeropen.com 